\title{
Diversity of Informal Housing in Bangkok and Ho Chi Minh City
}

\author{
Le Thi Thu Huong ${ }^{1}$, Le Thi Kieu ${ }^{2}$ \\ ${ }^{1}$ Montfort del Rosario School of Architecture and Design, Assumption University, Thailand; and Vietnamese-German University, \\ Vietnam \\ ${ }^{2}$ Institute of Constructive Design and Building Construction, Germany
}

\begin{abstract}
Industrialization and economic growth in Bangkok and Ho Chi Minh City have attracted many rural-to-urban migrants to these cities in the last decades. Consequently, the housing shortage has become one of the most critical issues in both cities, where many low-income migrants live in spontaneously developed areas with limited infrastructure and housing conditions. Through three case studies in each city, this study aims to reflect the diversity in types and qualities of informal housing in both cities at present. The case studies are selected based on the varieties in location, scale, and settlement characteristics, including the built environment, neighborhood facilities, and transportation system. Data and information are collected through site observation, photo-taking, quick interviews, and secondary sources. The findings show diversity in informal housing types such as temporary houses, old condominiums, container houses, and the like. These accommodations have limited living conditions such as inadequate spaces, poor facilities, unhealthy environment, and low safety. Even though this housing issue is not new in developing countries, the existence of this issue still raises a concern about housing for migrants in an urbanization context as it keeps challenging sustainability and inclusivity as the common objectives for housing development recently.
\end{abstract}

Keywords: Migration; Informal housing; Diversity; Bangkok; Ho Chi Minh City

\section{INTRODUCTION}

$\mathrm{T}$ The formation of informal settlement is one of the urban issues of megacities in Southeast Asia, resulting from their rapid economic growth that attracted a huge rural-tourban migration flow which the formal housing stock cannot accommodate. In Bangkok, economic development began in the 1960s with rapid population growth accelerating the influx of people coming from rural areas to the city [1]. Many informal settlements started to form around the centers of employment, such as industrial zones and markets since then. Through its urban development, the expansion of Bangkok has spontaneously occurred following the profits of landowners and developers [1]. At present, informal housing is still developing since the city keeps attracting rural migrants due to the development of service sectors with diversity in economic activities.

Similarly, the development of industrial zones in Ho Chi Minh City, together with the city's economic growth in the last decades after the economic reform (or Doi Moi in Vietnamese) in 1986, has attracted a massive flow of rural-to- urban migrants for better job opportunities. The shortage of existing housing stock in the city failed to accommodate these newcomers. Therefore, many low-income migrants must live in spontaneously developed areas where infrastructure and housing conditions are hardly adequate. In addition to the drives from industrialization and migration, the informal settlements in the city have also occurred due to the fragmented urban planning caused by various influences from private sectors and market forces [2].

Since Bangkok and Ho Chi Minh City have quite similar development contexts where migration has actively taken place, they are chosen for this study to reflect the associated housing problem. In both cities, as consequences of rapid urbanization, high concentration of industrial zones, and other economic activities, different types of migrants gradually form many informal settlements in and around the cities. The phenomenon has caused notable urban problems and challenged the development of these cities toward sustainability. This qualitative study, therefore, aims to reflect the diversity in types and qualities of informal housing through selected sites in these cities.

\section{LITERATURE REVIEW}

\section{A. Definition, Typologies, and Characteristics of Informal Settlements}

According to United Nations, informal settlements are defined as (1) "the areas where groups of housing units have been constructed on land that the occupants have no legal claim to, or occupy illegally" or (2) "the unplanned settlements and areas where housing is not in compliance with current planning and building regulations (unauthorized housing)" [3]. The latter is more popular used.

Regarding this definition of the United Nations, two factors to classify informal settlements are development rights and authorization. Even though the scheme of typology varies from study to study, they are generally fundamental factors to define whether a settlement is considered informal. According to these factors, there are several types of informal settlements such as notified slums, illegal/unauthorized colonies, resettlement colonies, squatters, urban villages, and so on $[4$, 5]. Summarizing these types in the context of Delhi, India, Ishtiyaq and Kumar have characterized them with limitations in authorization, absence of common facilities, poor 
approaches and failed redevelopment efforts of governments, high level of tenancy, high density, detrimental factors to safety and health, poor living conditions and so on [6]. In terms of spatial organization, informal settlements may vary in size, and some pocket slums in specific areas can be extended and densified gradually [6]. Housing in these settlements is found with awkward shapes of plots [1].

\section{B. Consequences of Informal Settlements}

The communities in informal settlements are vulnerable to significant health risks, disasters, and economic changes. Limited sanitation and poor drinking water quality expose the inhabitants to many diseases. Once they get sick, access to healthcare may be limited and expensive. Besides that, overcrowding can also contribute to increased stress, insecurity, violence, and other social issues, which are especially harmful for children [7]. People in the squatter areas also lack knowledge, information, and conditions to prevent disaster, causing them to be heavily impacted by flooding, typhoons, and extreme weather conditions. Moreover, due to their limited financial circumstances, they are sensitive to any economic-related changes that render them likely to stay poor. Some concerns such as occupation stability, fears of eviction, and poor living conditions are raised by the inhabitants [8]. It is complicated to overcome these without proper support from the government.

The development of informal housing also causes some major urban issues. Even though informal settlement development is inexpensive at the beginning, its activities may cost neighborhoods and the city considerable sums. While the most apparent costs often go to solve environmental issues and public health, other fees may be used for solving social problems. However, according to Ferguson, the informal settlement is no less expensive than formal-sector development due to these costs [9].

\section{Policies and Development Strategies in Relation to Informal Settlement}

Policies concerning informal settlements are interrelated and vary from country to country. A report by Margarita Greence summarized six main policy areas in the application: social housing, land policy, planning and regulation, information, governance, and financing [10]. As these policies relate to multiple aspects, they are implemented with strategies mentioned as follows.

Land clearance, or slum demolition, slum-razing, and bulldozer strategy, is common in many cities, especially for informal settlements formed in or close to city centers [10]. Land clearance aims to reduce the adverse effects of these areas, which causes spatial, environmental, and social fragmentation and utilizes the economic potentials. The settlers are given some opportunities to relocate legally elsewhere with compensation or a priority to register for their planned housing solutions, i.e., high-rise public housing areas in the suburban areas. The success of this strategy relies heavily on the definition of compensation schemes, duration and timing of the resettlement process, and livelihood changes. Even though land clearance seems to be an optimal strategy for urban redevelopment, it is outdated in the context of urban development nowadays due to specific negligence.

Besides relocation, residents can also remain at the land after an urban- or slum-upgrade with a better living quality. Though there is no definition for this concept as it changes over time, it generally refers to programs and policies relating to land rights, infrastructure delivery, participation enhancements, and political recognition [11]. Slum-upgrading projects vary from one place to another, based on their conditions and development objectives. In most cases, the implementation of these projects, i.e. of The World Bank in 1972, focuses on improving certain sectors of physical infrastructure in hopes to ensure basic needs and some other supports to reduce poverty [12]. However, nowadays, participatory and integrated upgrading strategies are preferred due to the recognition of micro-economic and socio-cultural development in fostering the sustainability of the resettlement projects.

The mentioned strategies have been evolving from one to another since the 1970s, as illustrated below [13]. The latter it is, the more these strategies aim to enhance the social and environmental values of the impacted informal settlements.

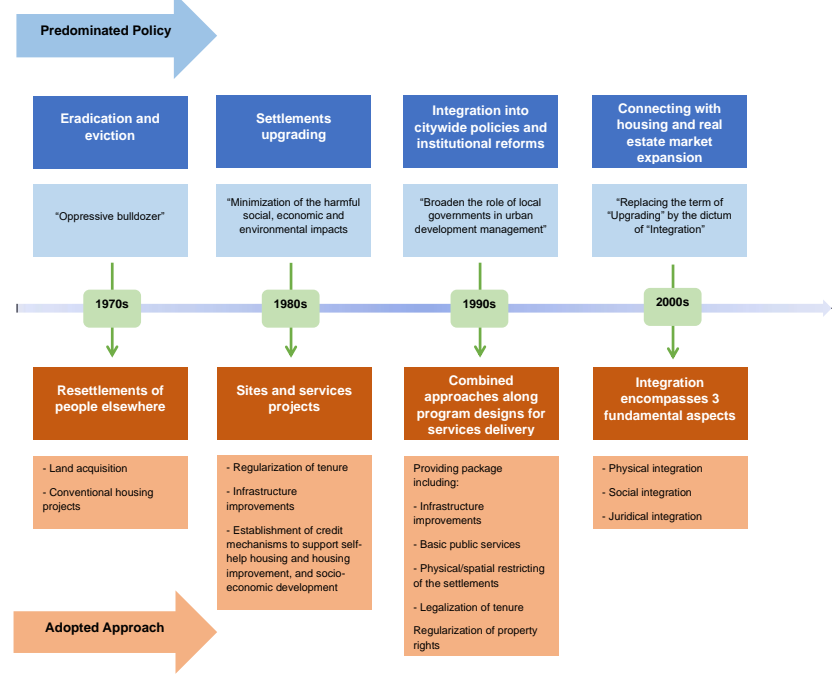

Fig. 1. Timeline of changes in policy and upgrading ideology worldwide [13]

\section{Good Practices in Dealing with Informal Settlements in Thailand and Vietnam}

Baan Mankong (secure housing) is a program on informal settlement in Bangkok, Thailand, implemented by CODI (Community Organizations Development Institute). The strategies - including upgrading, re-blocking and relocation applied in this program are varied in different neighborhoods due to its flexibility. The flexibility of this program effectively improved tenure security and housing conditions of the districts. Within the program, the community was encouraged to form their own savings groups, find solutions for low- 
interest loans, negotiate with the landowners, and implement what is needed and prioritized for them [14]. Due to selfarrangement and management, skillful builders gather in groups to help with house construction for their community and nearby communities. This solution is creative in saving costs and can make use of the valuable knowledge in the community itself. A network between communities, with the participation of public and private sectors, is built on sharing experiences and lessons learned and supporting each other. Being empowered by collective land ownership, households have transferred from informal to formal settlements and protected the communities from market forces [15]. The connection in these communities also encourages interaction, reduces hierarchic organization, and empowers the community itself. As reviewed by Bhatkal et. al, the lessons learned from Baan Mankong program are (1) placing the community at the center, (2) facilitating cooperation between stakeholders, (3) enhancing flexibility in finding solutions, (4) planning for urban expansion to avoid forming new informal settlements, and (5) ensuring inclusivity, even though it was still a challenge in Baan Mankong program [8].

For nearly a decade, the Tan Hoa Lo Gom neighborhood in Ho Chi Minh City, Vietnam, has been supported by Belgium to carry out its urban upgrading project. It was assessed as a significantly successful project with both tangible and intangible results. Tan Hoa Lo Gom canal was heavily polluted, which negatively impacted the living quality of the poor residents settling along the sides. Therefore, the upgrading project aimed to improve the environmental conditions of the area and develop housing and social aspects of the neighborhood. Hard measures were used within the project, including concreting alleys, lighting public areas, supplying drinking water, and collecting and treating waste [16]. A revisit to the project site six years later has confirmed the effectiveness of the infrastructure management and maintenance. The once polluted areas now have a new image. In addition to the physical improvement of tangible services, the project had a much broader impact on changing the status of the residents, self-creating sustainable operation and maintenance mechanisms, and improving interactions between authorities and the residents [17]. A condominium was built, which gave the residents the opportunity to own a flat without fearing flooding like before. Besides that, an alternative to housing solutions was to offer them a plot of land in a nearby area. Ownerships have entirely changed the residents' status and created positive effects on their participation in the project. Notably, it has been reported that the involvement of the local social workers has played a vital role in building trust between stakeholders. Such involvement even helped to improve the relocated social housing along with the use. The success of this project proves that capacity development and institutional strengthening are valuable concepts in slum upgrading.

\section{METHODOLOGY}

This paper provides a descriptive study that reflects the characteristics of informal settlements in Bangkok and Ho Chi Minh City through their housing typology and quality. Three cases are selected for investigation in each city, including both inner and outer city, based on the authors' knowledge of the cities (details of the cases will be provided in the next session). The studied dwellers are categorized based on their overall spatial organization, housing structure, and major construction materials. The housing quality covers several aspects that affect living quality, including space measurements, facilities, health-related conditions, and safety.

Data and information were collected from on-site observation, photo-taking, quick interviews with residents, and secondary documents. More specifically, in the case of Ho Chi Minh City, the site visit and interviews were conducted in December 2017 and January 2018, while these were done in February and March 2018 for Bangkok's case. The observation and photo-taking methods aimed to figure out the overall situation and physical attributes of the sites, observe the activities in the areas such as trading in spontaneous markets, informal services, and so on. Quick interviews with both landlords and tenants (2-3 persons per case) provided a better understanding of the site context, their perspectives on informal housing, and related issues concerning this kind of settlement. This overall socio-economic picture of the studied areas, due to the limited number of interviewees and short time of interviews, is considered not primary but supporting information in reflecting the characteristics of informal housing in both cities. Secondary documents were gathered from different sources and mainly used in the literature part. All data and information were compared, analyzed, and selected for presenting in this paper to figure out the characteristics of the cases. Data analysis was supported with mapping by using satellite images and spatial illustration based on the data and information collected.

\section{CASE STUDIES}

In this study, three areas in each city are selected based on many factors, including the differences in location, scale, and settlement characteristics such as the built environment, neighbourhood facilities, and transportation system. By observation and quick interviews with the residents, a diversity in job background is also noted (See Table 1).

Table I : Summary Of The Studied Sites In Bangkok And Ho Chi Minh City

\begin{tabular}{|c|c|c|c|c|}
\hline City & \multicolumn{2}{|l|}{ Location of the site } & Scale & $\begin{array}{c}\text { Overall } \\
\text { characteristics }\end{array}$ \\
\hline \multirow{3}{*}{ Bangkok } & Dindaeng & $\begin{array}{c}\text { Inner } \\
\text { city }\end{array}$ & $\begin{array}{c}\text { Large, } \\
1300 \text { flats } \\
(5000 \\
\text { people) }\end{array}$ & $\begin{array}{c}\text { - Since 1965, } \\
\text { renovated, planned } \\
\text { to demolish } \\
\text { - Major job of } \\
\text { settlers: street } \\
\text { vendors }\end{array}$ \\
\cline { 2 - 5 } & Mhalhong & $\begin{array}{c}\text { Outer } \\
\text { city }\end{array}$ & $\begin{array}{c}\text { Small, } 40 \\
\text { houses }\end{array}$ & $\begin{array}{c}\text { - Since 1988, } \\
\text { unregistered } \\
\text { - Major job of } \\
\text { settlers: workers (in } \\
\text { industry and } \\
\text { construction sites) }\end{array}$ \\
\hline
\end{tabular}




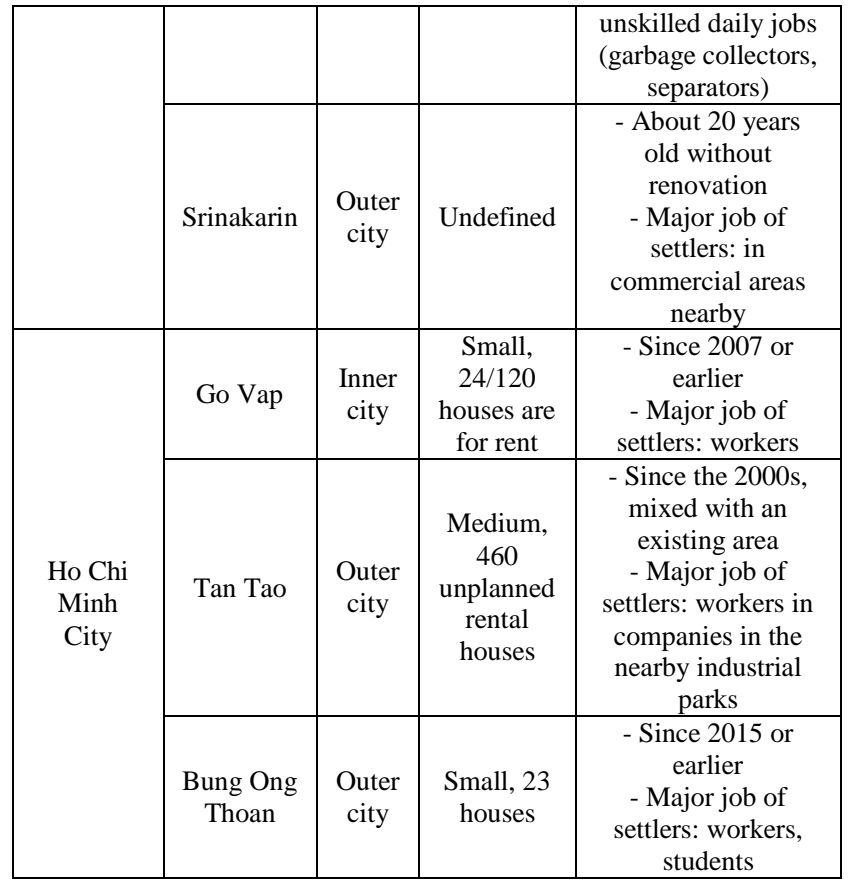

In Bangkok, one settlement in the inner city and two others in the outer city were selected (See Figure 2). They are located nearby the industrial zones and commercial areas. The size of the communities range from small ones with only 40 houses to large ones with 1300 flats (around 5000 inhabitants respectively). The construction of the oldest housing dates back to 1965 , while the latest one was developed 20 years ago. Two of the settlement areas were built without permission, and one is expecting a demolition after expiring its lifespan. The major livelihoods of people in these areas are unskilled laborers like street vendors, garbage collectors or separators, and sellers at the markets.

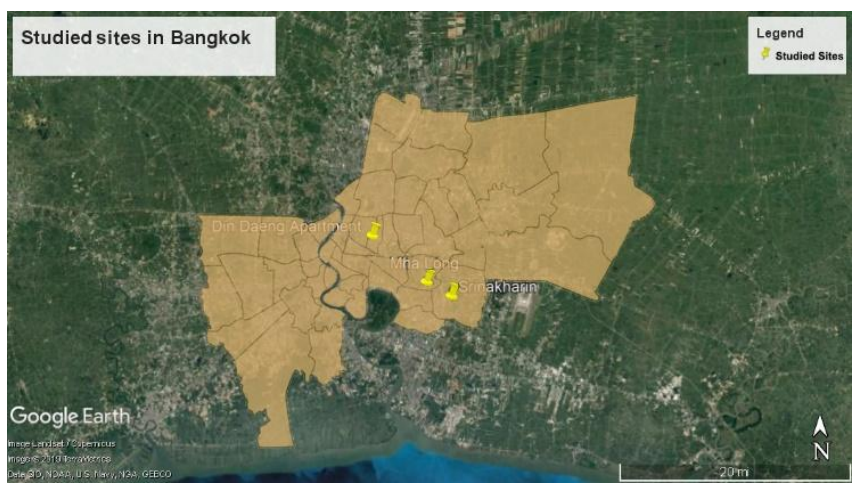

Fig. 2. Studied sites in Bangkok (Authors edited based on the image from Google Earth, 2019)

Similarly, one case in the inner city and two others in the outer city were selected in Ho Chi Minh City (See Figure 3). The community size in this city is relatively smaller than that in Bangkok, ranging from small size (23-24 houses) to medium size (460 houses). The studied informal settlements in Ho Chi Minh City are also younger than those in Bangkok, with the oldest one built in the 2000s. The houses are informally settled due to lack of permission for housing construction or poor management of the room renting business run by the residents. The people who live in these areas are either workers in the nearby industrial zones or students with limited financial affordability.

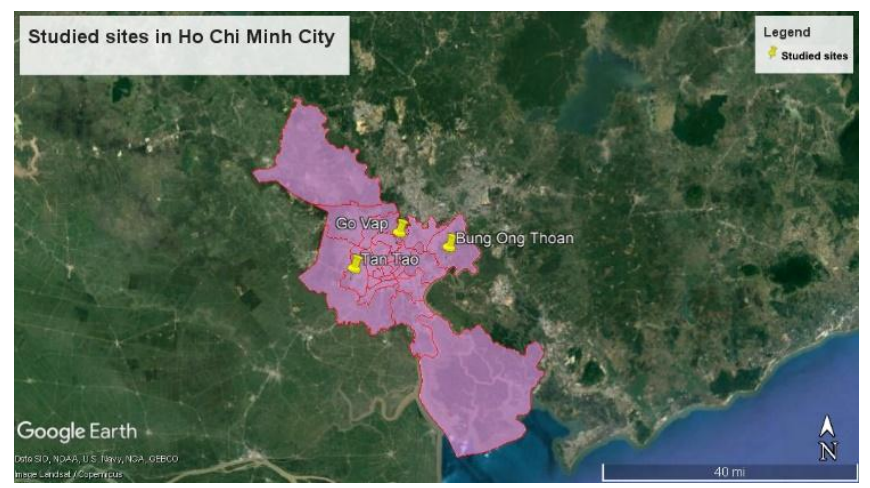

Fig. 3. Studied sites in Ho Chi Minh City (Authors edited based on the image from Google Earth, 2019)

\section{FINDINGS}

\section{A. Types of informal housing in Bangkok and Ho Chi Minh City}

Due to the complexity of the context and variety in locations, there are several types of informal housing with different spatial organizations in both cities. In Bangkok, old condominiums are commonly found in the city, housing a high density of low-income people. They occupy areas from the first floor upwards and save the ground floors mainly for public sharing such as parking, commerce, exercise, and community activities. For instance, four upper stories of Din Daeng Condominium are used for residents whose flats are connected through a single corridor, and some staircases are used as their horizontal and vertical walking routes. Each unit is designed as a studio house that relatively divides into the bathroom, terrace, and a shared space used for the kitchen, living room, and bedroom. (See Figure 4)

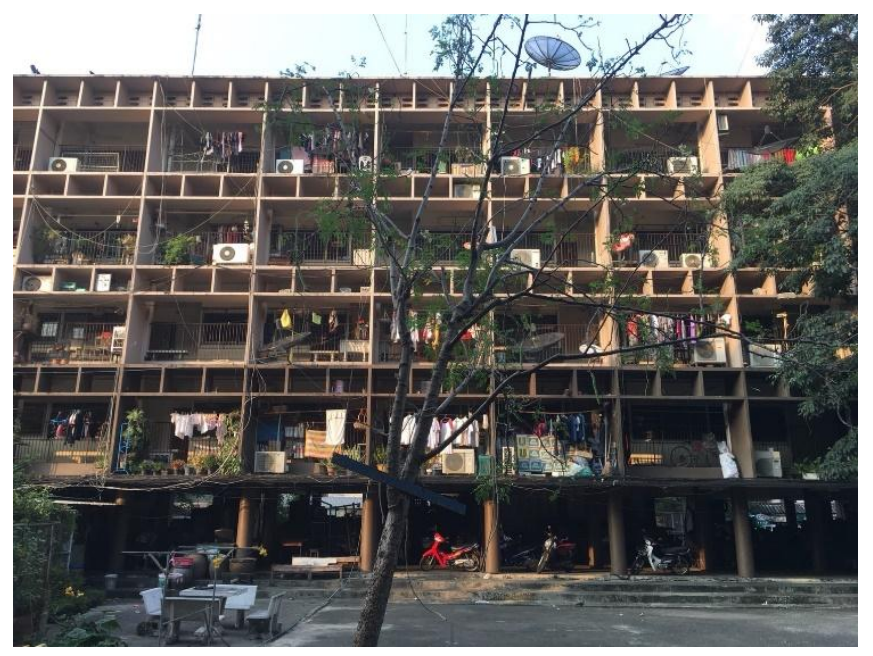

Fig. 4. Din Daeng Condominium, Bangkok (AR 4106, 2018) 
Another common type of informal housing in Bangkok is single temporal houses. Despite slight differences between these houses in the community in Mhalhong, they are spontaneously located within the studied area and are generally built with poor-quality materials. The most popular material is metal roofing panels used as roofs and walls in different sizes and types. Due to limited size, there is hardly any clear spatial separation inside the house. (See Figure 5)

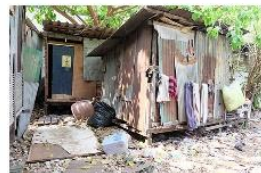

A

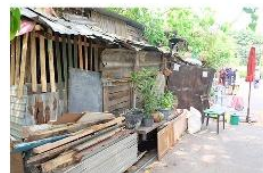

B

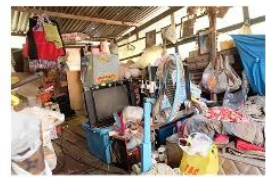

C
Fig. 5. Rental houses with poor-quality materials (A and B) and limited space (C) in Mhalhong, Bangkok (AR 4106, 2018)

In Srinakarin, Bangkok, the adjacent rooms built only for rent are mostly left unrenovated since their construction. They are designed as simple rooms connecting to each other through a hallway or corridor. This type of informal housing is also popular in Ho Chi Minh City with a similar principle in spatial organization. Figure 6 gives an example of how adjacent rooms for rent are arranged in the studied area in Go Vap District, Ho Chi Minh City. The corridor connecting all rooms shows a poor, insecure, and unsafe condition with a narrow width for the fire exit.

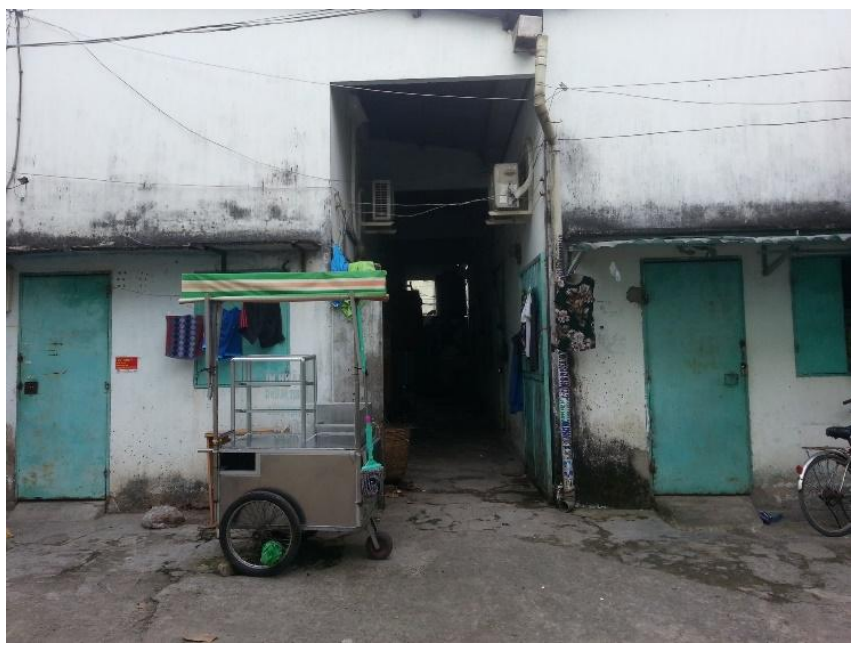

Fig. 6. Adjacent rooms for rent in Go Vap, Ho Chi Minh City (SUD 2017, 2017)

Close to Tan Tao Industrial Park in Ho Chi Minh City, there is a mixture of planned and unplanned rental houses in the area. This mixture results from the migration and insertion of the industrial workers of nearby factories into the existing residential neighborhoods. The informal settlements in this area, mainly rental rooms operated by the residents, are similar in type and structure to the cases of Srinakarin, Bangkok, and Go Vap, Ho Chi Minh City, as aforementioned. (See Figure 7)

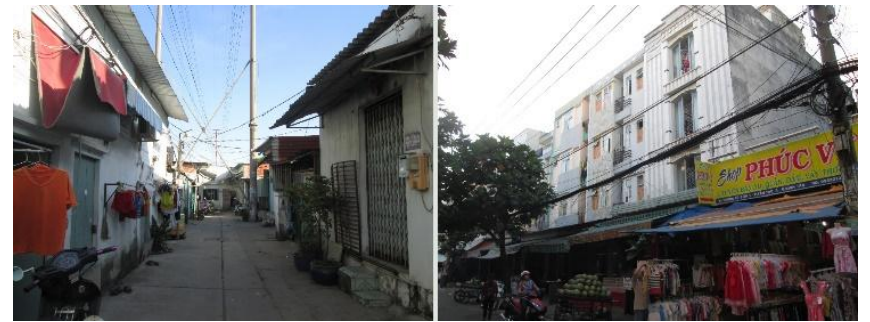

Fig. 7. Planned and unplanned houses for rent in Tan Tao, Binh Tan, Ho Chi Minh City (SUD 2017, 2017)

Another highly mixed area found in Ho Chi Minh City is the case of an area close to Bung Ong Thoan Street, District 9, that gathers both workers and students living in the same area. These spontaneous houses are built illegally as their owners do not have any development rights for the lands. The housing shape and construction materials are diverse, including metal covering panels, bricks, and unused containers (See Figure 8).

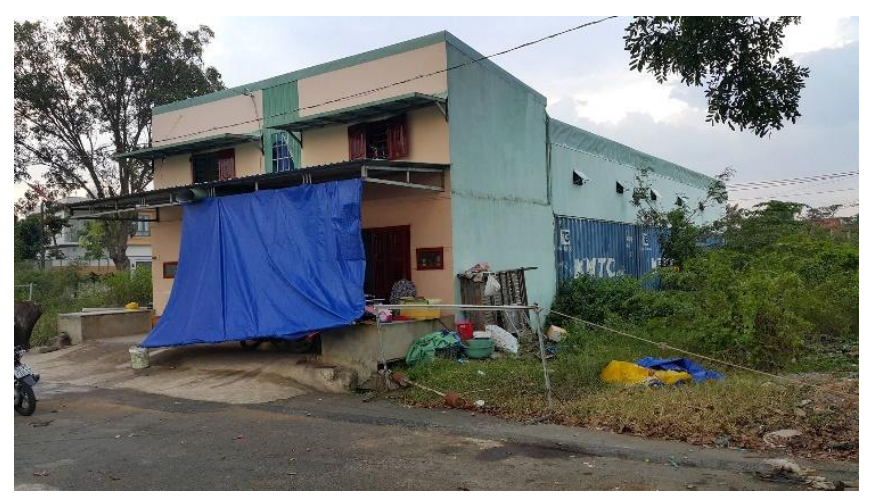

Fig. 8. A house made from bricks, metals, and old containers for adjacent rooms for rent in District 9, Ho Chi Minh City (SUD 2017, 2017)

B. Living conditions of informal housing in Bangkok and Ho Chi Minh City

Living conditions of informal housing in both cities are generally limited. The dwellings are characterized by inadequate spaces, poor facilities and structures, an unhealthy environment, and low safety. As this paper aims to reflect the diversity in informal housing types and qualities mainly through physical characteristics, the social and economic issues, especially the security problem in the informal housing areas, are not discussed. Each attribute will be discussed and illustrated by photos in the following sections.

\section{1) Inadequate spaces}

A lack of adequate space functioning as a basic room for living is commonly found at all studied sites. The living space is arranged as a studio house or room, which generally serves the needs of up to two persons. However, it is usually occupied by more inhabitants, commonly through a costsharing practice due to their limited budget (See Figure 9). 


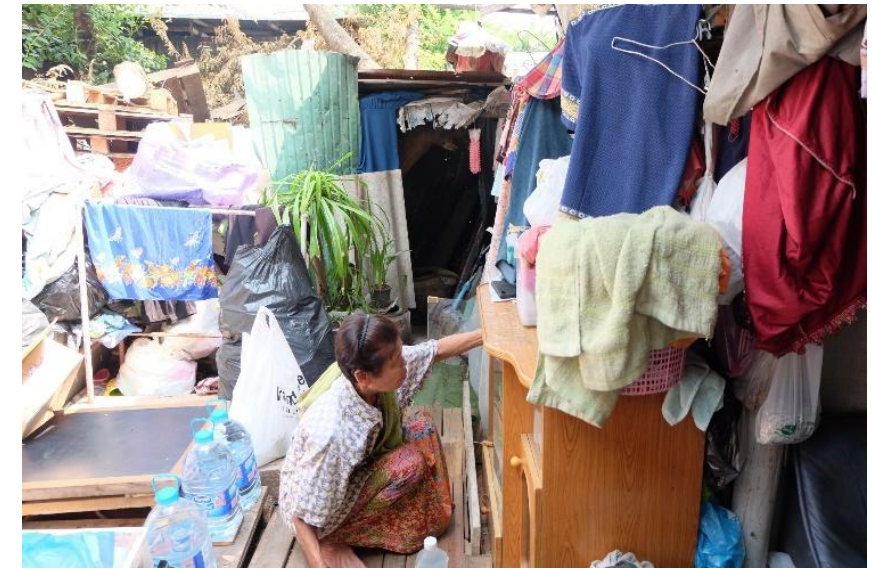

Fig. 9. Inadequate living space in a rental room in Mhalhong, Bangkok (AR 4106, 2018)

The average unit size in the studied areas ranges from 7.5 to 20 sqm. It is much smaller than the minimum standard area which is regulated as 28 sqm for accommodation in Thailand [18] and as 25 sqm for accommodation in Vietnam [19]. Due to the limitation in dwelling size and the high number of dwellers for cost-saving, it is questionable whether these housing units can ensure basic health conditions for the dwellers or not.

\section{2) Poor facilities}

Since these settlements are informally developed, there is a lack of even basic infrastructure and services to support living conditions. For instance, in Din Daeng Condominium, the old electricity system exposes people to many harmful risks, especially for the elderly and children. Water leakages often occur due to low maintenance, which causes inconveniences in daily life. The same situation happens in Go Vap rentalroom area where the electrical wires and appliance are messy along the corridor between two rows of rooms, potentially causing danger to the local inhabitants (See Figure 10).
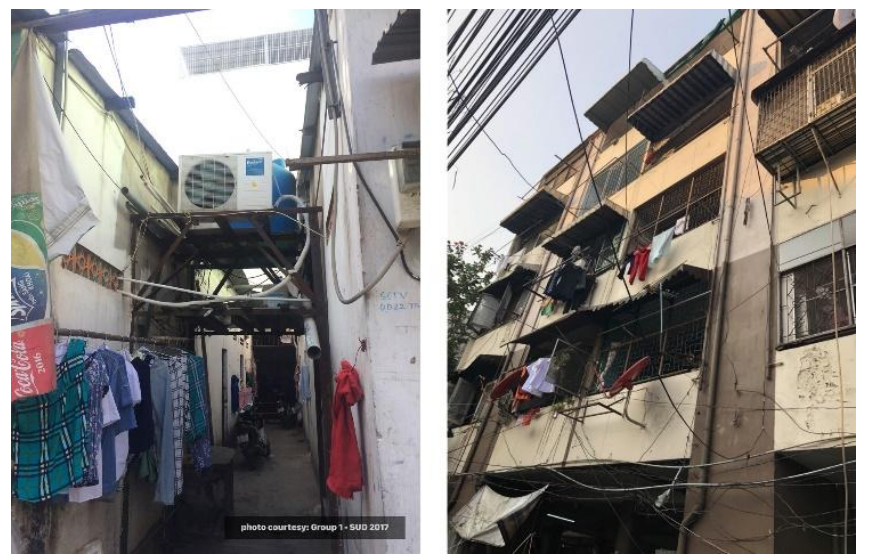

Figure 10: Messy electrical wires in Din Daeng Condominium, Bangkok (left) and Go Vap rental-room area, Ho Chi Minh City (right) (AR 4106, 2018 and SUD 2017, 2017)

In Mhalhong, water and electricity are not always accessible. During the interruption, people can buy water from some permanent households in the neighborhoods. However, the price is always overcharged at a far higher fee than the public water rate. For instance, according to a quick interview with the room tenants, while the official water rate for residence costs from THB 8.5 (USD 0.28) [20], they have to pay THB 12 (USD 0.40) per unit for buying water from the permanent households. The community close to Tan Tao Industrial Park in Ho Chi Minh City also has a similar problem of poor utility in their area. In the studied site in District 9, there is no connection from the informal housing area to the fundamental urban infrastructure like electricity and water. The tenants must self-connect their electricity and water lines to the main lines of infrastructure shared by their neighboring households, which usually comes at a higher cost.

In addition, poor lighting and aeration are also significant issues of informal housing. Besides the main door to access the houses, most of them have small windows or no window at all for lighting and ventilation. Notably, the middle rooms in a row of adjacent rooms have the poorest natural lighting and ventilation condition. In some other houses whose roofs or walls are made of metal materials, their thermal loads can reach very high in summertime. This condition may cause a thermal shock or exhaustion for the dwellers, especially in the hot seasons, and therefore, they usually have to turn on the fan at all times to avoid such problems (See Figure 11).

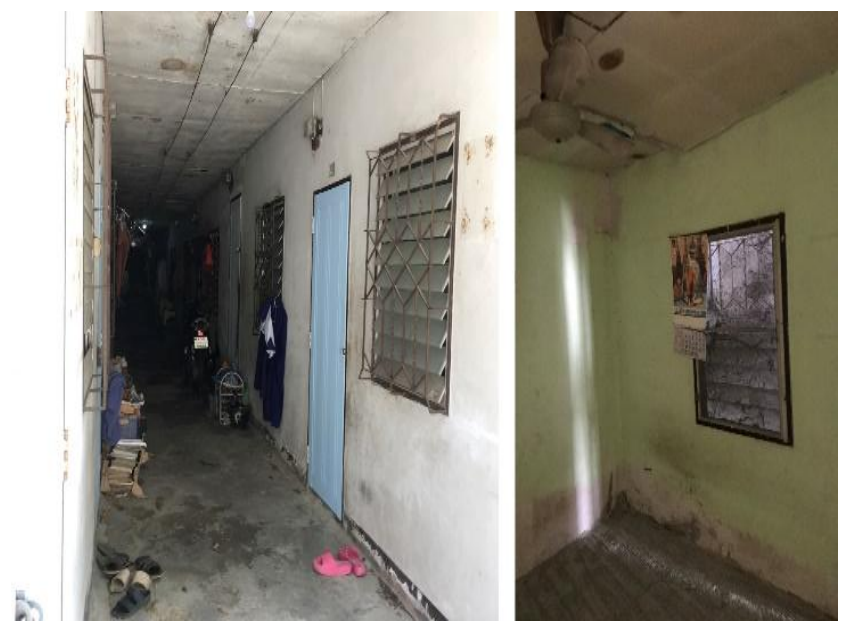

Figure 11: Poor lighting and aeration in the houses in Srinakarin, Bangkok (AR 4106, 2018)

\section{3) Unhealthy conditions}

In general, there is a low quality of life caused by a lack of space for living, limited electricity and water, poor lighting and aeration, and inadequate sanitation. It can be seen in many cases that the bathrooms and toilets are not adequately equipped and constructed. They are usually located in a corner of the room and surrounded by wall partitions. The contaminations from the uncovered toilets undoubtedly cause harmful effects on people's health, both physically and mentally (See Figure 12). 


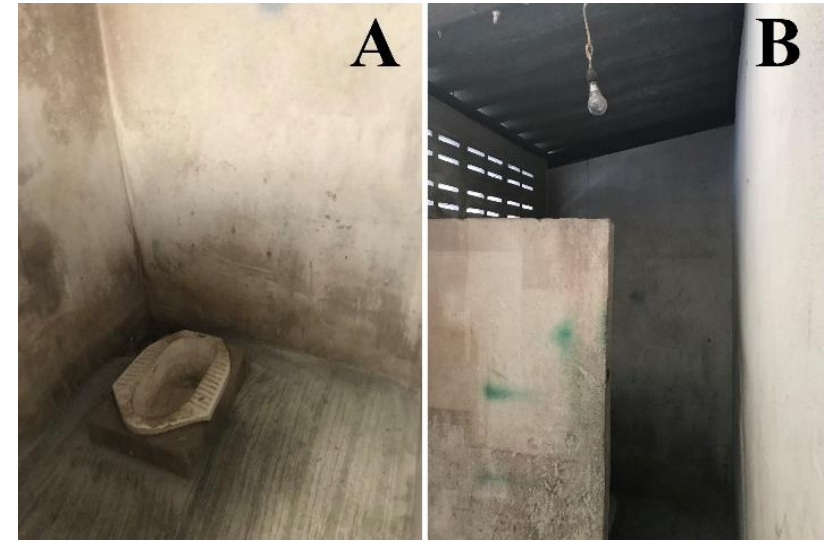

Figure 12: Bathroom with inadequate equipment (A) and low wall partitions (B) in Srinakarin, Bangkok (AR 4106, 2018)

Besides that, the increasing pollution from the environment also lower the living conditions of the informal settlements. Contaminated sources such as garbage, noise (Go Vap case), and air (Mhalhong case) expose people to an even higher risk of lung infection (See Figure 13).

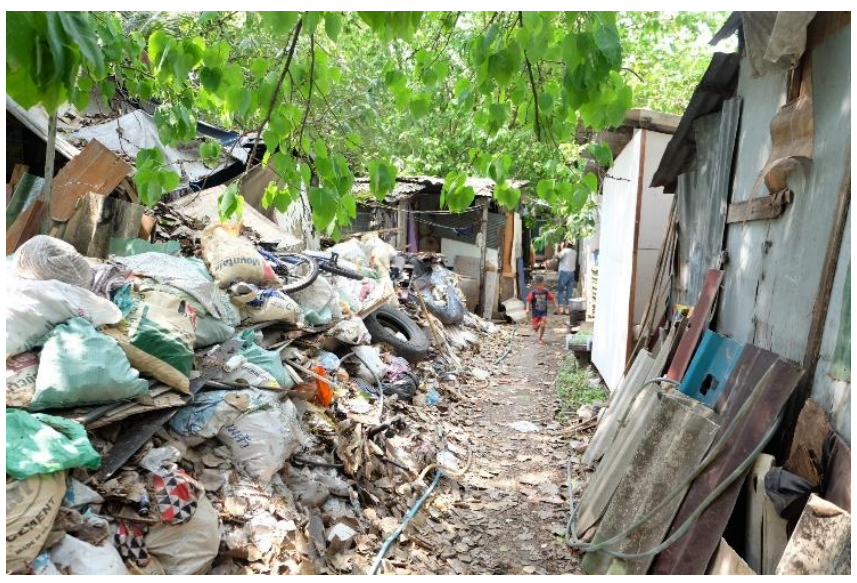

Figure 13: Garbage surround the living environment in Mhalhong community, Bangkok (AR 4106, 2018)

\section{4) Low safety}

Besides the inadequate facilities, in many cases, the houses have been in use for years without renovation or proper maintenance. For example, as the Din Daeng Condominium is expecting a demolishment for a new construction project, no improvement will be conducted to upgrade the houses. Cracks and rusted irons are commonly found at many places in the condominium. Similarly, the community in Srinakarin has been living there for more than 20 years without any renovation for better housing quality and safety. The downgrading houses caused by low durability in materials and structure have a high risk of collapsing and weak fire-fighting capacity, especially in the overcrowding areas like the studied sites. At the same time, the narrow corridor in the case of adjacent rooms may cause more loss and damages in fire accidents.

\section{DISCUSSION AND CONCLUSIONS}

Through six case studies, this study on informal housing in Bangkok and Ho Chi Minh City shows that the housing types and qualities are pretty diverse, with many limitations in housing conditions found in both cities. In Bangkok, old housing in the inner cities includes both temporal single houses and old condominiums. In contrast, in Ho Chi Minh City, container houses are assembled beside the temporal and permanent single dwellings. In both cities, inadequate spaces, poor facilities, unhealthy environmental conditions, and low safety are the common housing quality problems found in these dwellings.

The diversity in types and qualities of informal housing reflects an increasing development in response to a complex urban context in multiple aspects. From the variety in the location of these settlements, it is found that they have scattered in different places, not only around the industrial zones like they were commonly seen before during the industrialization period in both cities. This might be because demands from the higher number of migrants who are industrial workers and other sectors' employees have already exceeded the capacity of the areas around their workplaces; thus, they need to find additional locations for settlement. Furthermore, as the developed housing areas, even informal ones, around the employment zones become less affordable, this motivates the migrants to seek other places. In the meantime, rapid urban expansion accelerates infrastructure development, such as the road system in the urban fringes of both cities. Still, they have not been filled with residents accordingly. These urban vacancies then became inviting locations for new informal settlements in many forms of which the studied site in District 9, Ho Chi Minh City is one example. The container house on this site is illegal and temporary, but it can accommodate a group of poor migrants at least for a short period.

Moreover, another considerable consequence of these spontaneous settlements is the mixture of emerging informal housing and existing formal housing in the same neighborhood. In the social aspect, this phenomenon disturbs the existing area regarding community security, lifestyle conflicts between the old and new residents, etc., making the neighborhood hardly cohesive. In the economic aspect, even though the rental business benefits the residents, the overcrowded population with much higher demands than planned causes certain risks to the existing infrastructure, which may cost the cities to maintain or construct a new infrastructure system.

The development of informal settlements with their multiple adverse effects also presents a conflict in urban development. While many new housing projects are developed either by the public sector, private sector, or joint venture with a vision of livability and sustainability, informal housing has been growing in different locations with its diversity in types and qualities, as discussed in this paper. To some extent, this 
phenomenon raises a concern on whether the efforts in urban development should be reconsidered and reasonably shared between formal and informal housing management to attain better inclusivity in this sector. In conclusion, further investigation and analysis are recommended to reveal more insights into this phenomenon of informal settlements in order to provide better features and more in-depth information to the urban planner and governors. To a certain extent, this could help avoid possible slums emerging in both cities in the future.

\section{ACKNOWLEDGMENT}

The data and information used in this paper are partly collected by the students of Montfort del Rosario School of Architecture and Design, Assumption University, and Vietnamese-German University through their course assignments coded AR4106 and SUD2017 for Bangkok case and Ho Chi Minh City case respectively.

\section{REFERENCES}

[1] Sheng, Y.K., Leeruttanawisut, K.: Informal Settlements in Bangkok: Origins, Features, Growth and Prospects. In: Public Goods versus Economic Interests. ROUTLEDGE (2017).

[2] Huynh, D.: The misuse of urban planning in Ho Chi Minh City. Habitat International. 48, 11-19 (2015). https://doi.org/10.1016/j.habitatint.2015.03.007.

[3] United Nations: Glossary of Environment Statistics, Studies in Methods, Series F, (1997).

[4] Ali, S.: Environmental situation of slums in India. Uppal Pub. House, New Delhi (2003).

[5] Nangia, S., Thorat, S.: Slum in a metropolis: the living environment. Shipra Publications, Delhi (2000).

[6] Ishtiyaq, M., Kumar, S.: Typology of Informal Settlements and Distribution of Slums in the NCT of Delhi. India Journal. 7, (2010).

[7] World Health Organization: Environmental Health Indicators: Framework and Methodologies. Protection of the Human
Environment Occupational and Environmental Health Series, (1999).

[8] Bhatkal, T., Lucci, P.: Community-driven Development in the Slums: Thailand's Experience. Overseas Development Institute (2015).

[9] Ferguson, B.: The environmental impacts and public costs of unguided informal settlement; the case of Montego Bay. Environment and Urbanization. 8, 171-194 (1996). https://doi.org/10.1177/095624789600800218.

[10] Greene, M.: Literature Review: Main Policy and Programmatic Approaches for Slum Upgrading. (2010).

[11] Corburn, J., Sverdlik, A.: Urban Informal Settlement Upgrading and Health Equity. In: Slum Health. pp. 80-99. University of California Press (2016).

[12] Buckley, R.M., Kalarickal, J. eds: Thirty years of World Bank shelter lending: what have we learned? World Bank, Washington, DC (2006).

[13] Khalifa, M.A.: Evolution of informal settlements upgrading strategies in Egypt: From negligence to participatory development. Ain Shams Engineering Journal. 6, 1151-1159 (2015). https://doi.org/10.1016/j.asej.2015.04.008.

[14] Yap, K.S., De Wandeler, K.: Self-help housing in Bangkok. Habitat International. 34, 332-341 (2010). https://doi.org/10.1016/j.habitatint.2009.11.006.

[15] Boonyabancha, S.: Land for housing the poor — by the poor: experiences from the Baan Mankong nationwide slum upgrading programme in Thailand. Environment and Urbanization. 21, 309329 (2009). https://doi.org/10.1177/0956247809342180.

[16] Le, D.A., Legrand, B., Lint, J.V.: Tan Hoa Lo Gom - Building a new life. Presented at the 43rd ISOCARP Congress (2007).

[17] BTC: Unexpected social impact of an infrastructure project. (2014).

[18] Japan International Cooperation Agency, International Development Center of Japan, Pacet Corporation: Data collection survey on housing sector in Thailand. National Housing Authority (2013).

[19] Prime Minister: Decree No. 100/2015/ND-CP on Development and Management of Social Housing, (2015).

[20] Thailand Board of Investment: Cost of Doing Business in Thailand. 